\title{
SURFACE OXYGEN EXCHANGE PROPERTIES OF BISMUTH OXIDE-BASED SOLID ELECTROLYTES AND ELECTRODE MATERIALS
}

\author{
B.A. BOUKAMP, I.C. VINKE, K.J. DE VRIES and A.J. BURGGRAAF \\ Laboratory of Inorganic Chemistry, Materials Science and Catalysis, Department of Chemical Technology. \\ University of Twente, P.O. Box 217, 7500 AE Enschede, The Netherlands
}

Received 23 June 1988; accepted for publication 25 June 1988

\begin{abstract}
The surface oxygen exchange coefficient, $k_{5}$, has been measured for the solid solution $\left(\mathrm{Bi}_{2} \mathrm{O}_{3}\right)_{0.75}\left(\mathrm{Er}_{2} \mathrm{O}_{3}\right)_{0.25}$ and $\left(\mathrm{Bi}_{2} \mathrm{O}_{3}\right)_{0.6}\left(\mathrm{~Tb}_{2} \mathrm{O}_{3}\right)_{0.4}$ (abbreviated $\mathrm{BE} 25$ and $\left.\mathrm{BT} 40\right)$, using gas-phase ${ }^{18} \mathrm{O}$ exchange techniques. The activation enthalpy of $k_{\mathrm{s}}$ amounts to $\Delta E=110 \mathrm{~kJ} / \mathrm{mol}$ for BT 40 and $\Delta E=130 \mathrm{~kJ} / \mathrm{mol}$ for BE25. The magnitude of $k_{\mathrm{s}}$ for the purely ionic conducting BE25 is comparable with values obtained from electrode polarization $(I-V)$ measurements $(\Delta E=140 \mathrm{~kJ} / \mathrm{mol})$. The comparatively high $k_{\mathrm{s}}$ values show a $\left(P_{\mathrm{O}_{2}}\right)^{n}$ dependence on oxygen pressure with values of $n$ close to 0.5 , indicating surface control in the oxygen transport process. Bismuth oxide containing solid solutions show a large activity in the oxygen exchange reaction with the gas phase.
\end{abstract}

\section{Introduction}

The performance of oxygen ion conducting devices, such as oxygen pumps, solid oxide fuel cells (SOFC's) and mixed conducting semi-permeable oxygen membranes, depends strongly on the ionic conductivity of the oxide material and on the surface oxygen exchange rate. The first parameter has been subject of extensive studies. The surface oxygen exchange rate is especially important in electrolytes with small thickness but has, until recently, received much less attention as it is less accessible through electrochemical experiments. The surface exchange kinetics of solid (oxygen) electrolytes can be studied with electrochemical polarisation measurements in a three-electrode arrangement using porous (noble) metal electrodes. As a consequence the combination electrode/electrolyte surface is then probed. The choice of electrode material, however, can significantly influence the oxygen exchange kinetics, as was found for ceria- and zirconia-based electrolyte materials at temperatures below $1070 \mathrm{~K}$ [1].

Steele, Kilner and coworkers [2-4] were the first to study the surface oxygen exchange and diffusion kinetics of single and polycrystalline oxygen ion conducting oxides. Solid samples were exchanged in ${ }^{18} \mathrm{O}_{2}$ enriched oxygen gas at 500 and $700^{\circ} \mathrm{C}$ for a fixed period of time. Subsequently the tracer diffusion profile was measured with a dynamic secondary ion mass spectrometer (SIMS) [2]. Depth profiles of more than $10 \mu \mathrm{m}$ deep could be measured. Assuming a single rate determining step in the surface oxygen exchange and a semi-infinite diffusion condition the exchange rate and the (tracer) diffusion for oxygen could be obtained.

The remarkable results of these studies, summarized by Steele and coworkers [5], were (i) that for scandia-stabilised zirconia the exchange rate increased by a factor of 5 after bismuth implantation [4] and (ii) that the exchange rates for zirconiabased materials were a factor of $10^{3}$ smaller than deducted from electrochemical measurements using porous platinum electrodes [6], while (iii) for bismuth erbium oxides high and identical values were obtained for both methods, indicating a possible enhancement of the exchange kinetics by the bismuth ion.

In this presentation the temperature and pressure dependence of the surface oxygen exchange rate is presented of $\left(\mathrm{Bi}_{2} \mathrm{O}_{3}\right)_{0.75}\left(\mathrm{Er}_{2} \mathrm{O}_{3}\right)_{0.25}$ (abbreviated $\mathrm{BE} 25$ ), which is a pure ionic conductor with a very high conductivity [7], and of $\left(\mathrm{Bi}_{2} \mathrm{O}_{3}\right)_{0.6}\left(\mathrm{~Tb}_{2} \mathrm{O}_{3}\right)_{0.4}$ 
(abbreviated BT40), which is a mixed conducting oxide, also with high ionic and electronic ( $p$-type) conductivities [8]. For BE25 a comparison is made with the exchange current values obtained from electrode polarization $(I-V)$ experiments [9]. Here the exchange rate is measured by monitoring the ${ }^{18} \mathrm{O}$ ratio (number of atoms ${ }^{18} \mathrm{O}$ divided by total number of oxygen atoms in the gas phase) of the gas-phase with a quadrupole mass spectrometer during the isotope exchange. Preliminary NRA and (static) SIMS studies complement the obtained results.

\section{Instrumental setup and procedure}

\subsection{Materials preparation}

The BE25 and BT40 powders were prepared through a co-precipitation route followed by a calcining step. These powders were subsequently hydrostatically pressed into thick pellets of $1-2 \mathrm{~cm}$ diameter and length, and sintered in air. The optimized procedure for preparing dense and strong BE25 ceramics has been described recently by Kruidhof et al. [10,11]. The thus obtained pellets were more than $98.6 \%$ dense, based on a density of 8.96 $\mathrm{g} / \mathrm{cm}^{3}$ obtained from X-ray analysis. The bismuth terbium oxide samples were prepared in the same manner, details will be published elsewhere. The relative density for BT 40 was better than $98.8 \%$ (based on a "X-ray density" of $8.69 \mathrm{~g} / \mathrm{cm}^{3}$ ).

Of these pellets small discs were cut and polished to a thickness of 0.05 to $0.1 \mathrm{~cm}$ with a final polish with $0.3 \mu \mathrm{m} \mathrm{Al}_{2} \mathrm{O}_{3}$. The total sample surface area was between 1 and $2 \mathrm{~cm}^{2}$, while the oxygen content was about 0.7 to $1.4 \mathrm{mmol}$ per sample.

\subsection{Exchange system}

A schematic representation of the ${ }^{18} \mathrm{O}$ exchange system is given in fig. 1. The exchange cell can be evacuated and flushed with dried argon. The ${ }^{18} \mathrm{O}_{2}$ gas (Amersham International, $>97$ atom $\%{ }^{18} \mathrm{O}$ ) is contained in a small molecular sieve sorption pump from which it can be bled into, or pumped out of, the exchange cell. For sample equilibration regular, dried oxygen is supplied.

In the quartz cell the sample is suspended from the

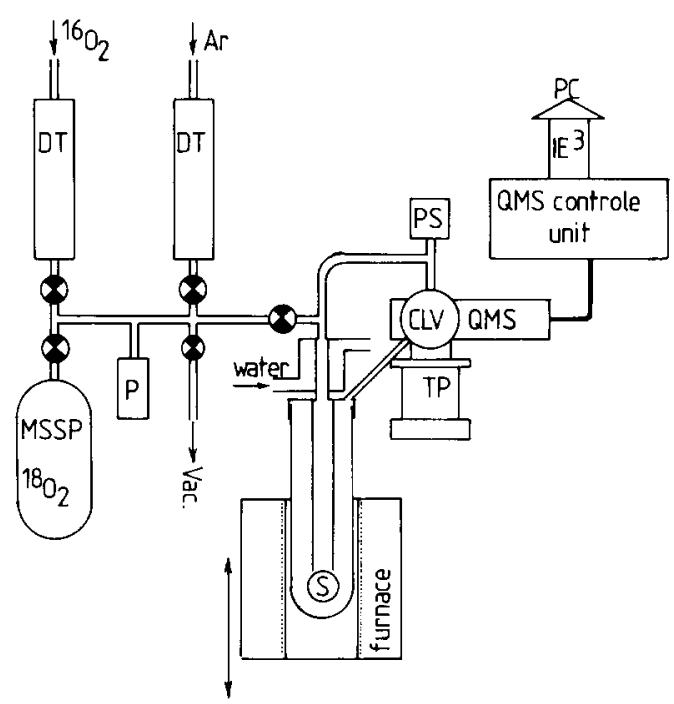

Fig. 1. Schematical representation of the ${ }^{18} \mathrm{O}$ exchange measurement system. MSSP $=$ molecular sieve sorption pump, QMS=quadrupole mass spectrometer, $T P=$ turbo pump, $\mathrm{CLV}=$ controled leak valve, $\mathrm{S}=$ sample, $\mathrm{PS}=$ electronic pressure sensor, $\mathrm{DT}=$ drying tower (molecular sieve), $\mathrm{P}=$ Pirani gauge, $\mathrm{PC}=$ personal computer.

(open) bottom of the inner quartz tube in a thin gold wire frame. It is assumed that the inner tube acts as a chimney, due to the forced cooling at its top. The chimney effect thus drives the gas circulation through the "pass through" controlled leak valve. The volume of the exchange cell and the connecting tubing is about $55 \mathrm{~cm}^{3}$, the pressure is measured with a straingauge type pressure sensor provided with a vacuum reference.

The removable, regulated furnace was designed to enable rapid heating of the cell, typically in less than $1 \mathrm{~min}$ for $10-30^{\circ} \mathrm{C}$ below the desired temperature, measured at the thermocouple. The exchange capacity of the empty cell was found to be negligible with respect to the exchange capacity of the samples currently studied.

During the exchange experiments a continuous gas sample is drawn from the controlled leak valve by the evacuated recipient of the quadrupole mass spectrometer (Balzers QMS/QMG 112). A turbo molecular pump unit provides an UHV background pressure of less than $5 \times 10^{-8} \mathrm{~Pa}\left(3.8 \times 10^{-10}\right.$ Torr $)$ under stand by conditions and better than $10^{-7} \mathrm{~Pa}$ with the quadrupole filament on. Measurements are 
generally performed with a total pressure of about $10^{-5} \mathrm{~Pa}$ in the quadrupole recipient. The control of the quadrupole and the data acquisition is realised through an IEEE interfacing system connected to a XT-compatible computer.

\subsection{Exchange protocol}

All samples were first pre-annealed at $750^{\circ} \mathrm{C}$ for $0.5 \mathrm{~h}$ in dry, pure oxygen at a pressure of about 0.2 atm in order to clean the surface and ensuring identically conditioned surfaces for all samples. The exchange cell was then rapidly cooled by submerging the quartz tube in cold water and subsequently evacuated and flushed with argon several times. Next an exact known amount of dry (natural) oxygen, neccesary to establish the required pressure under exchange conditions, was admitted in the cell and the sample was equilibrated at the desired "exchange" temperature for several hours (about $1-2 \mathrm{~h}$ for $750^{\circ} \mathrm{C}$ to more than $10 \mathrm{~h}$ at the lowest temperature). Again the sample was rapidly cooled to room temperature and the cell evacuated and flushed with argon.

Carefully the exact same amount of oxygen as used for the previous equilibration step, but now from the ${ }^{18} \mathrm{O}_{2}$ enriched oxygen reservoir, was admitted. The temperature dependence of the exchange rate was measured with a total oxygen pressure of about 0.2 $\mathrm{atm}$. For the pressure dependence pressures in the range 0.03 to $1.4 \mathrm{~atm}$. were used. The composition of the gas was measured and the sample rapidly heated to the exchange temperature. During the exchange the mass $32\left({ }^{16} \mathrm{O}_{2}\right), 34\left({ }^{16} \mathrm{O}^{18} \mathrm{O}\right)$ and 36 $\left({ }^{18} \mathrm{O}_{2}\right)$ quadrupole signals were measured continuously. At the end of the exchange the sample was again rapidly cooled to room temperature.

\section{Results and discussion}

\subsection{Exchange and diffusion kinetics}

Following, Steele et al. [3-5], a single rate determining step is assumed for the surface exchange of oxygen. The sample is supposed to be in thermodynamical equilibrium with the gas-phase so that the (equilibrium) oxygen fluxes in and out of the sam- ple are identical. The ${ }^{18} \mathrm{O}$ ratio in the gas-phase, $x$, is given by:

$$
x=\frac{P_{18 \mathrm{O}_{2}}+\left(P_{16 \mathrm{OO}_{18} \mathrm{O}}\right) / 2}{P_{18 \mathrm{O}_{2}}+P_{16(\mathrm{O}) \mathrm{8}(\mathrm{O})}+P_{16 \mathrm{O}_{2}}} \text {. }
$$

For the change of $x$ with time one can then write:

$\mathrm{d} x / \mathrm{d} t=-S k_{\mathrm{s}}\left(x-y_{\mathrm{s}}\right) / A$,

where $y_{\mathrm{S}}$ is the ratio ${ }^{18} \mathrm{O}$ in the solid at the surface, $S$ is the surface area in $\mathrm{cm}^{2}$ and $A$ is the moles of oxygen $(32,34$ and 36$)$ present in the gas-phase. Hence the dimension of $k_{\mathrm{s}}$ is $\mathrm{mol} \mathrm{s}^{-1} \mathrm{~cm}^{-2}$. In principle $y_{\mathrm{s}}$ depends on the (tracer) diffusion coefficient of the bulk material. For short times, i.e. for $\sqrt{D t} \ll d / 2$ where $d$ is the thickness of the sample, the semi-infinite boundary solution for $y_{\mathrm{s}}$, as presented by Steele and Kilner [2,3] must be used. With the large oxygen reservoir used by Kilner et al. [2], they could assume that the ${ }^{18} \mathrm{O}$ ratio remained constant in the gas-phase. If the characteristic length $\sqrt{D t}$ becomes in the order of $d / 2$ or larger, the finite length boundary conditions must be used, which will lead to a more flattened isotope profile in the bulk. This will be even more so if the surface exchange rate, $k_{s}$, is restricting the diffusion. As a first approximation, $y_{\mathrm{s}}$ in eq. (2) may then be replaced by $y$, which is the mean ${ }^{18} \mathrm{O}$ ratio in the bulk. Now the ratios $x$ and $y$ are related through the total amount of ${ }^{18} \mathrm{O}$ present:

$A x+B y=A x_{0}+B y_{0}$,

where $x_{0}$ and $y_{0}$ are the starting ${ }^{18} \mathrm{O}$ ratios in the gasphase and bulk respectively and $B$ is the number of "moles of oxygen" ( 16 and 18 ) in the bulk. For the bulk $y_{0}=0.002$, which is the natural background ${ }^{18} \mathrm{O}$ ratio. Inserting eq. ( 3 ) in eq. (2) and solving the differential equation leads to a classical diffusion equation:

$x(t)=x_{x}+\left(x_{1}-x_{x}\right) \exp \left[-S k_{\mathrm{s}}\left(A^{-1}+B^{-1}\right) t\right]$.

where $x_{\infty}$ is the equilibrium ${ }^{18} \mathrm{O}$ ratio at infinite time, which is of course equal for both gas-phase and bulk:

$x_{x}=y_{\infty}=\left(A x_{0}+B y_{0}\right) /(A+B)$.

Thus a plot of $\ln \left[\left(x(t)-x_{x_{0}}\right) /\left(x_{0}-x_{\infty}\right)\right]$ versus time should yield a straight line while $k_{\mathrm{s}}$ can be obtained from its slope.

In the gas-phase three types of oxygen molecules 
are present, ${ }^{18} \mathrm{O}_{2},{ }^{16} \mathrm{O}^{18} \mathrm{O}$ and ${ }^{16} \mathrm{O}_{2}$, with ratios $u, v$ and $1-u-v$, while $x=u+v / 2$. Due to the statistics of the recombination of adsorped oxygen atoms to molecules the equilibrium values for $u$ and $v$ will be given by:

$\frac{v^{2}}{u(1-u-v)}=4$.

Monitoring the change of these ratio can give extra information on the kinetics of the oxygen exchange, provided that no other surfaces in the exchange cell are active for dissociative adsorption.

\subsection{Exchange results}

Fig. 2 gives a typical example of a logarithmic representation of the quadrupole data of an exchange measurement. The value for the surface exchange coefficient, $k_{\mathrm{s}}$, can be obtained with considerable precision. The (macroscopic) surface area of the samples is estimated geometrically with an approximate error of $2-5 \%$. The oxygen content of the samples $(B)$ is calculated accurately from their weight, while the moles of oxygen in the gas-phase $(A)$ is determined from the pressure, temperature and estimated cell volume. The temperature dependence of $k_{\mathrm{s}}$ for $\mathrm{BE} 25$ and for BT40 are given in the Arrhenius plot of fig. 3. The $k_{\mathrm{s}}$ value obtained from SIMS depth profiling on exchanged BE25 (Steele and coworkers [5]) has been included also and fits very well with

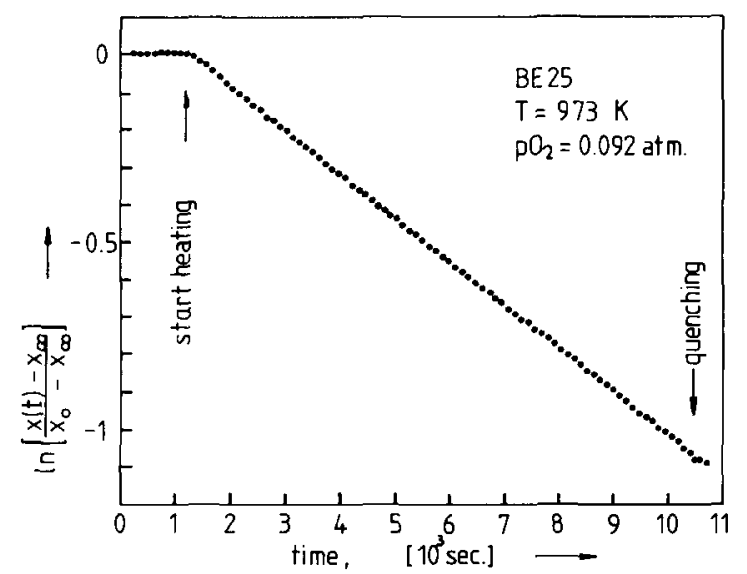

Fig. 2. Typical example of ${ }^{18} \mathrm{O}$ gas-phase exchange curve plotted as $\ln \left[\left(x(t)-x_{\infty}\right) /\left(x_{0}-x_{\infty}\right)\right]$ versus time. The slope is equal to $k_{s} S(1 / A+1 / B)$

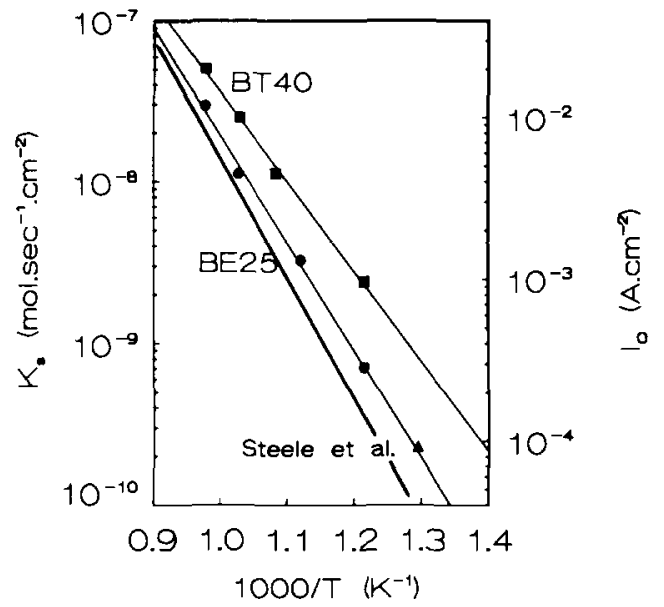

Fig. 3. Arrhenius plot of the temperature dependence of $k_{\mathrm{s}}$ for

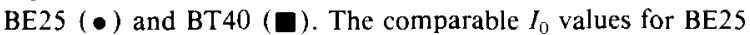
are represented by the heavy solid line. The $k_{\mathrm{s}}$ value for BE2S (A) reported by Steele et al. [5] has been included.

our data. Estimated activation enthalpies are $110 \pm 10$ $\mathrm{kJ} / \mathrm{mol}$ for BT40 and $130 \pm 5 \mathrm{~kJ} / \mathrm{mol}$ for BE25.

For the purely ionic conducting BE25 material the surface exchange coefficient can be compared directly with the oxygen exchange current obtained from $I-V$ polarization measurements [9]. These electrochemical measurements were performed in air using porous gold electrodes that cover the electrolyte surface for roughly $50 \%$. The $I_{0}$ values, obtained with a NLLS-fit procedure [12] from the $I-V$ curves, are also represented in fig. 3 , the activation enthalpy of $140 \pm 5 \mathrm{~kJ} / \mathrm{mol}$ is close to the value obtained from the exchange experiments. If the $I_{0}$ and the $k_{\mathrm{s}}$ values pertain to the same rate determining step in the exchange mechanism, then they should differ only by a factor of $4 \mathrm{~F}$ :

$k_{\mathrm{s}}=I_{0} / 4 \mathrm{~F}$.

Taking into account the partial coverage of the surface by the electrode, the correspondence between the $k_{\mathrm{s}}$ values and the exchange current densities is remarkable.

\subsection{Pressure dependence of $k_{s}$}

The pressure dependence of $k_{\mathrm{s}}$ was measured at $823 \mathrm{~K}$ for BE25 and at $973 \mathrm{~K}$ for BE25 and BT40. The useful pressure range in the current exchange 


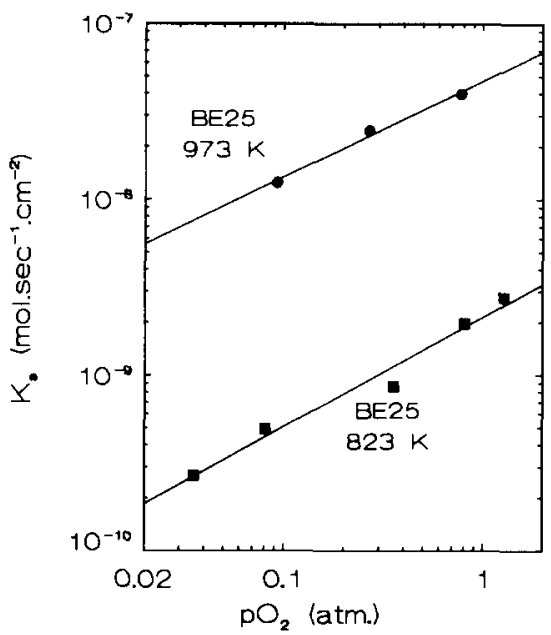

Fig. 4. Pressure dependence of $k_{\mathrm{s}}$ for BE25 at 823 and $973 \mathrm{~K}$.

system is 0.03 to $1.4 \mathrm{~atm}$. The $\log -\log$ plot of fig. 4 for BE25 and of fig. 5 for BT40 clearly show a $\left(P_{\mathrm{O}_{2}}\right)^{\prime \prime}$ behaviour for $k_{\mathrm{s}}$, with $n$ close to 0.5 ( 0.6 for BE25 at 823, and 0.54 for BE25 and BT 40 at $973 \mathrm{~K}$ ).

The same, inverse, pressure dependence was observed by Verkerk et al. [6] for the electrode resistance (which is inversely proportional to the exchange current) measured at $970 \mathrm{~K}$ in BE20 and BE40 $\left(\mathrm{Bi}_{2} \mathrm{O}_{3}\right.$ with respectively 20 and $40 \mathrm{~mol} \%$ $\mathrm{Er}_{2} \mathrm{O}_{3}$ ) samples provided with porous platinum electrodes. They concluded that the mass transport (diffusion ) of adsorbed surface oxygen to be the rate determining step.

Recent electrochemical measurements of the exchange current densities of BE25 [9] using porous gold electrodes showed also a $P_{\mathrm{O}_{2}}$ power dependence of 0.56 at $1000 \mathrm{~K}$, identical to the $P_{\mathrm{O}_{2}}^{n}$ dependence

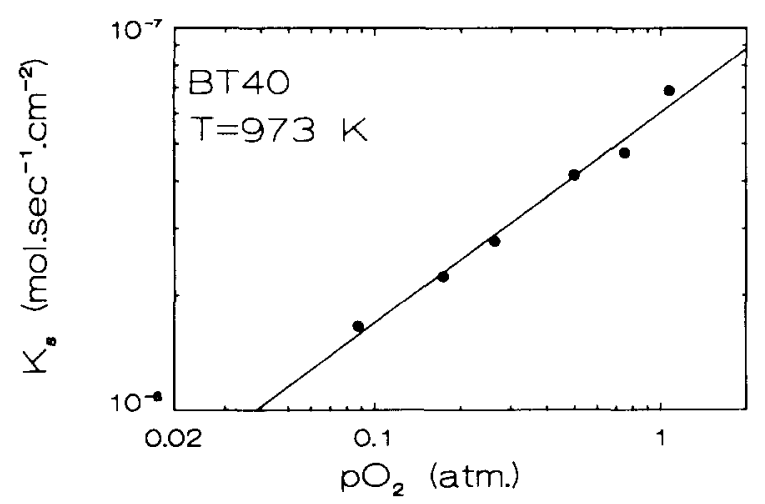

Fig. 5. Pressure dependence of $k_{3}$ for BT40 at $973 \mathrm{~K}$. measured for $k_{\mathrm{s}}$. With decreasing temperatures, however, the electrochemically measured value decreases to about 0.15 at $650 \mathrm{~K}$, while for $k_{\mathrm{s}}$ the power remains nearly constant. This possibly indicates some influence of the electrode (material) on the exchange kinetics at lower temperatures.

A $P_{6,2}^{1 / 2}$ dependence was also observed by Dou et al. [13] for the permeation of oxygen through thin samples of calcia-stabilized zirconia, where they assumed the charge transfer reaction:

$\mathrm{O}_{\mathrm{ads}}+\mathrm{V}_{\mathrm{o}}^{\ddot{ }} \rightleftharpoons \mathrm{O}_{\mathrm{o}}^{\times}+2 \mathrm{~h}$.

to be rate determining. For thick samples a $P_{1 / 2}^{1 / 2}$ dependence was found which could be explained by bulk diffusion control.

Further information on the exchange kinetics might have been obtained from the change of the ratios $u$ and $v$ of the masses 36 and 34 in the gas-phase. Unfortunately the quartz ampoule of the exchange cell has an active surface for dissociative adsorption of oxygen, leading to a rapid equilibration of $u$ and $v$ according to eq. (6). The quartz ampoule, however. does not participate in the exchange of ${ }^{18} \mathrm{O}$ between the gas and the bulk of the solid, as no appreciable change with time was found in the total ${ }^{18} \mathrm{O}$ ratio $(x=u+v / 2)$ in an exchange experiment without a sample.

\subsection{Diffusion profile}

The analysis of the exchange measurements is based on the assumption that the ${ }^{18} \mathrm{O}$ diffusion profile in the bulk can be regarded to be flat. With $\mathrm{Nu}$ clear Reaction Analysis (NRA) measurement the ${ }^{18} \mathrm{O}$ concentration profile can be measured over a depth of about 1 micron, using the ${ }^{18} \mathrm{O}(P, \alpha){ }^{15} \mathrm{~N}$ nuclear reaction. Preliminary measurements do show a rather flat ${ }^{18} \mathrm{O}$ concentration profile. The mean concentration of ${ }^{18} \mathrm{O}$ in the sample, after the exchange has been stopped, can easily be calculated from the initial and final ${ }^{18} \mathrm{O}$ concentration in the gas-phase. Static SIMS measurements on one sample of BT 40 showed a surface isotope ratio of $y_{\mathrm{s}}=0.54$, almost equal to the calculated mean value of $y=0.55$. This also implies a flat profile.

Finally, if not the correct value for the oxygen content of the sample, $B$, is entered in eq. (4), a deviation from the linear behaviour in the graphic rep- 
Table 1

Surface oxygen exchange coefficients, $k_{\mathrm{s}}$, and corresponding $I_{0}$ values for BT40 and BE25, normalized to $P_{O_{2}}=0.21$ atm. The electrochemically obtained $I_{0}$ values for BE25, measured in air, are given for comparison.

\begin{tabular}{|c|c|c|c|c|c|}
\hline \multirow[b]{2}{*}{$\begin{array}{l}\text { Temp. } \\
\text { (K) }\end{array}$} & \multicolumn{2}{|l|}{$\begin{array}{l}\text { Sample } \\
\text { BT } 40\end{array}$} & \multicolumn{2}{|l|}{ BE25 } & \multirow{2}{*}{$\begin{array}{l}\mathrm{BE} 25 \\
I_{0} \\
\left(\mathrm{~A} / \mathrm{cm}^{2}\right)\end{array}$} \\
\hline & $\begin{array}{l}k_{\mathrm{s}} \\
\left(\mathrm{mol} / \mathrm{cm}^{2} \mathrm{~s}\right)\end{array}$ & $\begin{array}{l}I_{0} \\
\left(\mathrm{~A} / \mathrm{cm}^{2}\right)\end{array}$ & $\begin{array}{l}k_{\mathrm{s}} \\
\left(\mathrm{mol} / \mathrm{cm}^{2} \mathrm{~s}\right)\end{array}$ & $\begin{array}{l}I_{0} \\
\left(\mathrm{~A} / \mathrm{cm}^{2}\right)\end{array}$ & \\
\hline 750 & $6.3 \times 10^{-8}$ & $2.4 \times 10^{-2}$ & $3.7 \times 10^{-8}$ & $1.4 \times 10^{-2}$ & $7.7 \times 10^{-3}$ \\
\hline 700 & $2.5 \times 10^{-8}$ & $9.7 \times 10^{-3}$ & $1.4 \times 10^{-8}$ & $5.4 \times 10^{-3}$ & $3.3 \times 10^{-3}$ \\
\hline 650 & $1.4 \times 10^{-8}$ & $5.2 \times 10^{-3}$ & & & $1.3 \times 10^{-3}$ \\
\hline 550 & $3.0 \times 10^{-8}$ & $1.2 \times 10^{-3}$ & $8.3 \times 10^{-10}$ & $3.2 \times 10^{-4}$ & $1.4 \times 10^{-4}$ \\
\hline 500 & & & $2.3 \times 10^{-10}$ & $8.9 \times 10^{-5}[5]$ & $3.6 \times 10^{-5}$ \\
\hline
\end{tabular}

resentation of fig. 2 is observed for large exchange times. The effect of a sloping diffusion profile could be regarded as only part of the sample oxygen being involved in the exchange, i.e. a smaller value for $B$, which would thus lead to a deviation from linear behaviour in the representation of fig. 2 . Hence the consistency of the results strongly suggests a flat tracer profile in these samples.

\section{Conclusions}

The direct measurement of the gas-phase isotope ratios in ${ }^{18} \mathrm{O}$ exchange experiments can give valuable information on the surface oxygen exchange rate, $k_{\mathrm{s}}$. The pressure dependence of $k_{\mathrm{s}}$ gives information on the rate determining step in the exchanges process. For both BE25 and BT 40 a square root dependence on oxygen (partial) pressure was found, while the bulk diffusion profile was very flat. This can be explained by assuming a surface control in the oxygen transport process. The results obtained here confirm the notion that bismuth strongly enhances the surface oxygen exchange rate leading to high values for $k_{\mathrm{s}}$, at $1000 \mathrm{~K}$ roughly a factor of $10^{3}$ larger than found for bare zircon yttrium oxides [5].

\section{Acknowledgement}

The authors wish to thank Mr. H. Kruidhof and Mr. J. Snoeyenbos for preparing the samples. Dr. F.
Jansen and Dr. H. Weijers of the KEMA Institute in Arnhem are acknowledged for the preliminary SIMS measurements. Special thanks go to Dr. D. Boerma and Dr. P. Smulders of the LAN, University of Groningen, for their ongoing efforts and support in the NRA measurements and data analysis.

\section{References}

[1] D.Y. Wang and A.S. Nowick, J. Electrochem. Soc. 126 (1979) 1155; 126 (1979) 1166;128 (1981) 55.

[2] D.S. Tannhauser, J.A. Kilner and B.C.H. Steele, Nucl. Instrum. Methods in Phys. Res. 218 (1983) 504.

[3] J.A. Kilner, B.C.H. Steele and L. Ilkov, Solid State Ionics 12 (1984) 12.

[4 ] B.C.H. Steele, J.A. Kilner, P. Dennis and D. Tannhauser, Brit. Ceram. Proc. 34 ( 1984 ) 53.

[5] B.C.H. Steele, J.A. Kilner, P.F. Dennis, A.E. McHale, M. van Hemert and A.J. Burggraaf, Solid State Ionics 18/19 (1986) 1038 .

[6] M.J. Verkerk, M.W.J. Hammink and A.J. Burggraaf, J. Electrochem. Soc. 130 (1983) 70.

[7] M.J. Verkerk and A.J. Burggraaf, J. Electrochem. Soc. 128 (1981) 75 .

[8] B.A. Boukamp, M.P. van Dijk, K.J. de Vries and A.J. Burggraaf, Adv. Ceram. 23 (1987) 447.

[9] I.C. Vinke, J.L. Backiewicz, B.A. Boukamp, K.J. de Vries and A.J. Burggraaf, to be published.

[10] H. Kruidhof, K. Seshan, B.C. Lippens Jr., P.J. Gellings and A.J. Burggraaf, Mater. Res. Bull. 22 (1987) 1635.

[ 11 ] H. Kruidhof, K. Seshan, G.M.H. van de Velde, K.J. de Vries and A.J. Burggraaf, Mater. Res. Bull. 23 (1988) 371.

[12] B.A. Boukamp, I.C. Vinke, K. Seshan, K.J. de Vries and A.J. Burggraaf, Solid State Ionics 28-30 (1988) 1187.

[13] S. Dou, C.R. Masson and P.D. Pacey, J. Electrochem. Soc. $132(1985) 1843$. 